\title{
Informação, Memória e Documento: estudo sobre as associações japonesas em Marília, São Paulo
}

\author{
Natacha Kajimoto \\ Universidade Estadual Paulista, Faculdade de Filosofia e Ciências, Marília, SP, Brasil \\ kajimotofunai@hotmail.com \\ Lidia Eugenia Cavalcante \\ Universidade Federal do Ceará, Departamento de Ciência da Informação, Fortaleza, CE, Brasil \\ cavalcantelidiaeugenia@gmail.com \\ Marcia Cristina Carvalho Pazin Vitoriano \\ Universidade Estadual Paulista, Faculdade de Filosofia e Ciências, Marília, SP, Brasil \\ marciapazin@marilia.unesp.br
}

Resumo: Os primeiros japoneses chegaram a Marília em 1926 e, já em 1930, foi fundada a primeira associação japonesa nessa cidade, o Nikkey Clube de Marília. Em 1945, outra associação foi fundada, a Associação Esportiva e Cultural Okinawa de Marília (AECOM). Essas duas associações trouxeram contribuições essenciais para a disseminação da cultura japonesa e para a construção da identidade dos imigrantes em Marília e região. Nesse âmbito, esta pesquisa tem como objetivo analisar como se deu o desenvolvimento dessas associações, em relação à cultura informacional, à memória e à identidade japonesa, uma vez que não foram identificados estudos sobre essa contribuição para a referida comunidade e para os brasileiros que vivem em Marília. Trata-se de uma pesquisa de abordagem qualitativa, de caráter exploratório, usando como procedimentos metodológicos a pesquisa bibliográfica e documental no acervo histórico do Nikkey Clube de Marília e da Associação Esportiva e Cultural Okinawa de Marília (AECOM), que constituem o universo de pesquisa deste trabalho. Como resultados, demonstramos a importância da criação e manutenção das associações de japonesas como mecanismo de preservação da memória e de transmissão de conhecimento entre seus membros.

Palavras-chave: Imigração japonesa e cultura informacional; Informação; Marilia (SP); Memória e identidade; Preservação da memória.

Information, Memory and Document: Study on Japanese associations in Marilia, Sao Paulo

Abstract: The first Japanese arrived in Marilia in 1926, and already in 1930, was founded the first Japanese association in this city, the Nikkei club Marilia. In 1945, another association was founded, the Sports and Cultural Association Okinawa Marilia (AECOM). These two associations brought essential contributions to the spread of Japanese culture and the construction of identity of immigrants in Marilia and region. In this context, this research aims to analyze how was the development of these associations, in relation to the information culture, memory and the Japanese identity, since they were not identified studies on this contribution to that community and to Brazilians living in Marilia. This is a qualitative research, exploratory, using as methodological procedures bibliographic and documentary research on the historical collection of the Nikkei club Marilia and Sports Association and Cultural Okinawa Marilia (AECOM), which constitute the research universe this work. Thus, we have demonstrated the importance of creating and maintaining the Japanese associations as a means of preserving the memory and transmission of knowledge among its members.

Keywords: Information; Japanese immigration and information culture; Marilia (SP, Brazil); Memory and identity; Memory Preservation.

Información, memoria y documento: estudio sobre las asociaciones japonesas en Marília, São Paulo Resumen: Los primeros japoneses Ilegaron a Marília en 1926 y, ya en 1930, fue fundada la primera asociación japonesa en esa ciudad, el Nikkey Club de Marília. En 1945, otra asociación fue fundada, la Associação Esportiva e Cultural Okinawa de Marília (AECOM). Esas dos asociaciones trajeron 
contribuciones esenciales para la diseminación de la cultura japonesa y para la construcción de la identidad de los inmigrantes en Marília y la región. En ese ámbito, esta investigación tiene como objetivo analizar cómo se dio el desarrollo de esas asociaciones, en relación a la cultura informacional, a la memoria y a la identidad japonesa, toda vez que no fueron identificados estudios sobre esa contribución para la referida comunidad y para los brasileños que viven en Marília. Se trata de una investigación de abordaje cualitativo, de carácter exploratorio, usando como procedimientos metodológicos la investigación bibliográfica y documental en el acervo histórico del Nikkey Club de Marília y de la AECOM, que constituyen el universo de investigación de este trabajo. Como resultados, demostramos la importancia de la creación y mantenimiento de las asociaciones de japonesas como mecanismo de preservación de la memoria y de transmisión de conocimiento entre sus miembros.

Palabras clave: Información; Inmigración japonesa y cultura informacional; Marilia (SP, Brasil); Memoria e identidad; Preservación de la memoria.

\section{Introdução}

Nesta pesquisa, estuda-se como a criação das associações de imigrantes japoneses na cidade de Marília, São Paulo, tendo como momento fundador a imigração para a região, influenciou na formação de uma identidade a partir da memória e da preservação de documentos produzidos e acumulados por elas.

A justificativa em desenvolver este estudo se dá pelo fato de que a região de Marília foi importante rota de imigração japonesa por causa das fazendas de café ali existentes e das matas que existiam para serem desbravadas. A região foi, ainda, uma das que mais receberam imigrantes japoneses no período que se estende por toda a primeira metade do século XX. Também, há o fato de, até o momento, serem poucas as fontes de informação produzidas e identificadas sobre como esses imigrantes agiram para fazer com que a identidade e a cultura japonesas não se perdessem, mesmo estando tão longe da terra natal.

Em todas as culturas encontram-se instituições criadas e legitimadas por variados motivos e apropriações, onde as pessoas buscam seus interesses e costumes com os quais se identificam. Por esse motivo, estudar essas instituições pelo viés da memória e da identidade é importante para conhecer melhor o meio pesquisado e compreender a importância que essas ações têm para o desenvolvimento da sociedade em que estão inseridas.

Sob essas perspectivas, o estudo tem como objetivo principal identificar o papel das associações japonesas na construção da memória, identidade e cultura dos imigrantes japoneses em Marília e, ainda, analisar como se dá o processo de guarda e apropriação da memória, a partir das ações desenvolvidas por essas associações e do registro documental por elas produzidos e preservados.

Esta investigação foi realizada mediante abordagem qualitativa, de caráter exploratório, compreendendo como universo de pesquisa as comunidades japonesas dessa 
cidade, mais especificamente aquelas vinculadas à Associação Nikkey Clube de Marília e à Associação Esportiva e Cultural Okinawa de Marília.

Os primeiros imigrantes japoneses chegaram a Marília em 1926. Já em agosto de 1930, fundaram a primeira associação japonesa na cidade, hoje conhecida como Nikkey Clube de Marília. Essa Associação funcionou durante dez anos ininterruptamente quando teve suas atividades paralisadas, em consequência de determinações estratégicas dos países aliados que participavam da Segunda Guerra Mundial.

As atividades associativas somente foram reiniciadas em agosto de 1945, após o término da Segunda Guerra. E, assim, surge oficialmente a Associação Nipo-Brasileira de Marília, que foi o berço do Nikkey Clube, fundado em 1 de dezembro de 1991.

Naquele mesmo ano, outra associação japonesa foi fundada. A Associação Esportiva e Cultural Okinawa de Marília (AECOM), um espaço para reunir os imigrantes conhecidos como okinawanos, provenientes da região de Okinawa, uma ilha localizada ao sul do Japão.

A pesquisa foi desenvolvida a partir do levantamento histórico-documental mediante estudo das fontes de informação que fazem parte do acervo das duas associações ou de famílias japonesas moradoras de Marília, pois entendemos tratarem-se de fontes de pesquisa indispensáveis para obtenção de importantes indícios sobre o processo de imigração japonesa para a região.

Esperamos, com esta pesquisa, colaborar para a compreensão do papel das associações japonesas instaladas em diversas cidades do Estado de São Paulo, a partir do estudo daquelas instaladas em Marília, e o que elas representam na construção da identidade e da cultura da imigração japonesa no Brasil.

\section{Cultura, identidade e memória}

Discutiremos, aqui, os conceitos de memória e identidade e suas diferentes abordagens, de modo a compreender as relações existentes com a temática aqui pesquisada. Ao enfocarmos esses conceitos, analisamos, também, as suas dimensões individuais e coletivas na complexa construção de uma possível "cultura japonesa" como representação no passado e que, no presente, se manifesta fortemente nos costumes, valores e nos modos de vida desse povo.

Para recompor a memória e a identidade, muitas vezes, nos utilizamos da memória dos outros, de modo que os acontecimentos, que foram esquecidos por nós, sejam retomados e nos façam relembrar fatos importantes do passado. O que outros indivíduos lembram, pode ajudar a reconstituir um tempo esquecido com o passar dos anos. 
Halbwachs (1990, p. 53) salienta que,

Não estamos ainda habituados a falar da memória de um grupo, mesmo por metáfora. Parece que tal faculdade não possa existir e durar a não ser na medida em que está ligada a um corpo ou a um cérebro individual. Admitamos, todavia que haja, para as lembranças, duas maneiras de se organizar e que possam ora se agrupar em torno de uma pessoa definida, que as considere do seu ponto de vista, ora distribuir-se no interior de uma sociedade grande ou pequena, de que elas são tantas outras imagens parciais. Haveria então memórias individuais e, se quisermos, memórias coletivas. Em outros termos, o indivíduo participaria de duas espécies de memória.

Devemos lembrar, porém, que toda memória é seletiva, ou seja, às vezes os indivíduos, por algum motivo, fazem questão de esquecer ou relembrar de fatos ocorridos. Ressaltamos, ainda, que existe a memória coletiva e a memória individual, e que uma se beneficia da outra.

Mas, afinal, quais são os elementos que constroem a memória individual e a memória coletiva? Na memória individual, são aqueles fatos que foram vividos pessoalmente, o que aconteceu a nós mesmos, quem somos, e o que nos afeta como indivíduos e constrói nossa identidade. Já a memória coletiva, destaca-se por aqueles fatos que podem não terem sido vividos diretamente pelos indivíduos e sim herdados pelo grupo ou comunidade da qual ele faz parte. Às vezes, o indivíduo nem participou de tal evento por não ter ocorrido na época em que ele viveu, mas de tanto ouvir contar sobre tal acontecimento e ganhar legitimidade no grupo, ele já não é mais capaz de saber se participou ou não (POLLAK, 1992).

Para Halbwachs (1990), a memória individual não está inteiramente isolada e fechada aos demais acontecimentos. Uma pessoa, para evocar seu próprio passado tem, frequentemente, necessidade de fazer apelo às lembranças dos outros.

Como afirma Pollak (1992, p. 202),

[...] critérios como acontecimentos, personagens e lugares, conhecidos direta ou indiretamente, podem obviamente dizer respeito a acontecimentos, personagens e lugares reais, empiricamente fundados em fatos concretos. Mas, pode se tratar também da projeção de outros eventos.

Desta forma, a memória individual ou coletiva, ao ser organizada, pode evidenciar projeção, transferência ou desinformação, de acordo com a importância do momento vivido por cada indivíduo ou pelo grupo. Como vimos em Hobsbawn (1997, p. 9), muitas vezes, as memórias de algumas "tradições" que parecem ou são consideradas antigas mostram-se bastante recentes, quando analisadas detalhadamente. Consideremos que a invenção de tradições é 
essencialmente um processo de formalização e ritualização, caracterizado por referir-se ao passado, mesmo que apenas pela imposição da repetição (HOBSBAWN, 1997).

Como nem todas as tradições são duradouras, muitas até são esquecidas, devemos nos atentar sempre em como surgem ou se estabelecem, e, para tanto, temos que recorrer à memória coletiva para entendê-las. Como a memória coletiva é mais organizada, pelo fato de ser a memória de um povo ou comunidade específica, muitas vezes, constitui acervos organizados, guardados em instituições de memória e disponibilizados para consulta.

Podemos dizer, então, que as tradições são inventadas quando há uma mudança social que afeta a antiga tradição, fazendo com que esta perca grande parte da sua capacidade de adaptação e flexibilidade. Quando isso ocorre, geralmente são feitas adaptações para preservar os antigos costumes em condições novas. Porém, se pesquisarmos nas memórias do passado de qualquer tradição, sempre encontraremos semelhanças com a presente.

Podemos afirmar, ainda, que a identidade é construída em referência aos outros, para que haja uma aceitação e credibilidade, e isso só será possível a partir da negociação direta com o interlocutor ou interlocutores. Mas, a memória coletiva e a identidade são geralmente negociadas e podem ser compreendidas como sendo essência de um grupo ou um indivíduo.

A identidade e a cultura são constituídas por aquilo que tem significados para os indivíduos, ou seja, que é originada deles, e construída pelo processo civilizatório que une os sujeitos em grupos ou comunidades. Algumas identidades, porém, podem ser formadas por meio de uma instituição dominante, que são aquelas instituições que só vão assumir qualquer condição quando e se os atores sociais internalizarem a sua vivência, o que vai resultar na construção do seu significado e papéis sociais, ou seja, os papéis que cada indivíduo assume na sociedade influenciam o comportamento das pessoas dependendo do que elas vão vivenciar em um determinado momento.

Sobre isso, Castells $(1999$, p. 22) destaca o que para ele vai significar o conceito de identidade,

\footnotetext{
No que diz respeito a atores sociais, entendo por identidade o processo de construção de identidade com base em atributo cultural, ou ainda um conjunto de atributos culturais inter-relacionados, o(s) qual(is) prevalece $(\mathrm{m})$ sobre outras fontes de significado. Para um determinado indivíduo ou ainda um ator coletivo, pode haver identidades múltiplas. No entanto, essa pluralidade é fonte de tensão e contradição tanto na auto-representação quanto na ação social.
}

Podemos, então, afirmar que, nós nos identificamos com os nossos pares por meio da cultura e, de acordo com a cultura na qual o indivíduo está inserido, ele irá construir uma identidade. A cultura define a identidade de um povo, e a identidade é a identificação desse 
povo em relação aos demais e também a identificação deles com sua própria cultura e memória. Os pontos de identificação entre os indivíduos diferenciam os que pertencem a esta ou aquela cultura.

Segundo Pollak (1992, p. 204), "[...] é perfeitamente possível que, por meio da socialização política, ou da socialização histórica, ocorra um fenômeno de projeção ou identificação com um determinado passado tão forte que podemos falar de uma memória quase herdada". Existem acontecimentos que marcam muito uma região ou um grupo, fazendo com que essa memória seja transmitida ao longo dos anos, de geração a geração.

Ainda para Pollak (1992), podemos ver que a memória não é constituída somente por meio de acontecimentos, ela é principalmente composta por pessoas, personagens. Estes seriam os protagonistas dessas memórias, vivenciadas ou herdadas. Personagens nem sempre conhecidos pelos indivíduos, e que podem nem fazer parte do tempo que está sendo vivido, mas passam a estarem presentes na história e na memória do grupo.

Outro ponto comum na memória coletiva são os lugares de memória (NORA, 1993) ligados à vida do indivíduo em coletividade, que traz lembranças pessoal e comunitária, e estão relacionados a espaços e acontecimentos vividos em grupos, podendo ou não ter um tempo cronológico determinado. É o caso de fatos que marcaram muito a vida de um indivíduo e que, por esse motivo, ficaram guardados em sua memória, mesmo não se lembrando da data exata em que ocorreu. Há, também, lugares distantes que não fazem parte diretamente da vida de uma pessoa, mas podem tornar-se parte importante da memória de um grupo, ou para o próprio indivíduo, seja por ter herdado ou por pertencimento, como o caso dos japoneses e seus descendentes que vivem no Brasil.

\section{Contexto da imigração japonesa no Brasil}

No Brasil, a história dos imigrantes japoneses inicia-se na última década do Século XIX, quando ocorreram as primeiras relações entre os dois países. Nessa época, o Japão buscava resolver questões nacionais relacionadas a modernização, que teve início com a chamada Restauração Meiji (1868-1912), colocando um fim ao longo período de reclusão da Era Tokugawa.

No período da hegemonia Tokugawa (1600-1867), anterior à Era Meiji, se concluiu o processo de unificação do Japão, sob um poder central. Essa unificação só foi possível depois de anos de lutas, até que a autoridade e a ordem do xogunato fossem finalmente estabelecidas. O xogunato é também chamado de governo dos generais, onde o xogum é visto 
como o chefe militar, que não substitui a posição do imperador, porém, de fato, é quem detém o poder político.

Com o Japão organizado hierarquicamente e fechado às relações exteriores, houve um desenvolvimento sem as influências ocidentais. Optando-se pelo isolamento, o Japão começou a se desenvolver em ritmo singular, se comparado aos países do ocidente. Juntamente com a agricultura, dentro de alguns feudos, aconteceu o desenvolvimento da manufatura que alimentou o comércio interno e aumentou a produtividade agrícola. Por conseguinte, produzindo mais, a população crescia $1 \%$ ao ano, onde começou uma desproporção entre quantidade de habitantes e terras disponíveis tornando, assim, as cidades, que antes eram vilarejos, em grandes centros, e o desenvolvimento do comércio levou à superação do sistema feudal japonês, tendo como consequências a perda do valor das antigas regras até então estabelecidas, contribuindo também para que o xogunato chegasse ao fim e dando início a restauração do poder imperial.

Em 1868, o Estado volta ao poder e inicia-se a Era Meiji. A Restauração Meiji foi o retorno do poder aos imperiais e a introdução do país na realidade mundial. Para que isso se tornasse possível, o Japão precisava adequar-se às exigências externas para ganhar força junto ao capitalismo e ao cenário político-externo.

Segundo Sakurai e Coelho (2008), o Japão buscava adquirir um rápido posicionamento entre as novas potências mundiais e, para tanto, várias transformações foram promovidas na política e na economia, tais como a inauguração de um governo constitucional, além da implantação de reformas de base, como no âmbito da educação que promoveu a alfabetização em massa da população, ou como no âmbito da economia que iniciou a tributação de bens produzidos no campo, trazendo a monetarização para regiões que ainda utilizavam o escambo.

Desse modo, vários proprietários se endividaram e foram obrigados a deixar suas terras e a migrarem para os centros urbanos. Esse fato gerou o aumento da população nas cidades que, por sua vez, em um país com pouca área cultivada, ocasionou a escassez de alimentos. Assim, muitos japoneses buscaram regiões além-mar, como o Havaí e a costa oeste dos Estados Unidos, visando fugir dessa situação.

O Peru foi o primeiro país da América Latina a manter relações diplomáticas com o Japão, sendo os japoneses contratados para a lavoura de cana-de-açúcar e algodão. Em 1899, porém, passam a ser hostilizados assim como nos Estados Unidos e acabando, também, em 1936, com a proibição da vinda de novos imigrantes para aquele país. 
Com o Tratado de Amizade, Comércio e Navegação, firmado em 5 de novembro de 1895, entre o Japão e o Brasil, os dois países passam a estabelecer relações diplomáticas e, assim, começa a se pensar nas possibilidades da vinda de japoneses para terras brasileiras.

Oficialmente, em 18 de junho de 1908, chegam ao Porto de Santos os primeiros imigrantes japoneses a bordo do navio Kasato-Maru, primeira embarcação a trazer trabalhadores japoneses ao Brasil. Estes, como era de se esperar, chegaram trazendo valores e costumes de sua cultura. Para eles, seria por pouco tempo que ficariam no Brasil, somente o tempo de adquirirem riquezas e voltarem ao Japão.

A imigração aconteceu como uma solução que o governo japonês encontrou para conter o problema demográfico que o Japão apresentava e que já estava começando a dar sinais de superpopulação. Com a aceleração no desenvolvimento industrial, o país começava a sofrer uma queda na sua produção agrícola.

Um dos fatores que diferenciavam a imigração para o Brasil era o de que se aceitavam somente famílias com presença de adultos, crianças e idosos, de ambos os sexos. Porém, cada família tinha que ter pelo menos três pessoas aptas ao trabalho. Para tanto, como explica Handa (1987), a maior parte dos imigrantes se agrupara apenas proforma naquilo que se chamou de "família composta", somente para a finalidade de obterem autorização para imigrar.

Vieira (1973) afirma que a imigração japonesa para Marília tem seu início em 1926. Em 1930, um ano após a instalação do município de Marília, foram ali localizadas 273 famílias japonesas, das quais 37 famílias $(13,55 \%)$ habitavam na zona urbana e $236(86,45 \%)$ na zona rural, número que aumentara gradativamente até atingir, em 1941, um total de 2.882 famílias. Dessas, 600 famílias, $(20,82 \%)$ viviam na zona urbana e 2.282 (79,18\%) na zona rural.

A imigração japonesa no Brasil, nos moldes em que ocorreu, proporcionou aos imigrantes um ambiente propício ao desenvolvimento de mecanismos de construção de uma memória coletiva que, além de colaborar com a manutenção de costumes e valores, proporcionava também espaços de acolhimento para os recém-chegados ou para aqueles que viriam ao longo dos anos. Em Marília, as associações de imigrantes cumpriram importante papel neste sentido.

\section{As Associações de Imigrantes Japoneses em Marília (São Paulo)}

$\mathrm{Na}$ busca para compreender a memória e a identidade dos japoneses que vivem no Brasil, mas especificamente aqueles que se instalaram na região de Marília (São Paulo), desde 
o processo migratório iniciado no começo do século $\mathrm{XX}$, visamos apresentar os percursos trilhados por eles, a partir da fundação de associações nessa região.

As associações ou Nihonjin-kai, como são chamadas pelos descendentes de japoneses, surgiram com o intuito de se fundar escolas voltadas para os filhos dos imigrantes. Fato curioso que salienta a intenção de se criar escolas nos moldes da cultura japonesa é apontado por Silva (2008), ao destacar que todo o material e métodos didáticos utilizados nas nihon gakko (escolas japonesas) eram importados do Japão.

Com o intuito de manter viva a cultura japonesa, os imigrantes residentes na cidade de Marília criaram associações que contribuíram para a manutenção de seus valores e identidade. Essas associações foram fundadas após um ano da vinda dos imigrantes japoneses para Marília. A primeira em agosto de 1930, denominada Marília Nihon-jin-kai e a outra em outubro daquele mesmo ano, denominada Marília Chuo Nihon-jin-Kai. Ambas tinham a mesma proposta, organizar uma escola japonesa e unir todas as famílias, bem como mediar o relacionamento entre os japoneses e os brasileiros.

Para Vieira (1973), a dualidade teria resultado da existência de dupla liderança. Essas duas associações estavam organizadas e, cada uma, tinha seu chefe. Porém, como os imigrantes residentes em Marília carregavam com eles o preconceito pelos okinawanos, o fato da associação Marília Nihon-jin-Kai ter como um dos fundadores um okinawano a presença dele como membro dessa associação resultava na não aceitação por parte de alguns chefes de família, o que agravou ainda mais a divisão deste grupo, que ficou dívida pelos líderes da seguinte forma: quem gostava da Marília Nihon-jin-kai ficava com ele, se não, ia para o líder da Marília Cho Nihon-jin-kai.

É importante destacar, contudo que, de um lado, estava o desejo de manter os padrões e valores tradicionais e orientações sociais e culturais voltadas para o Japão; do outro, havia uma compreensão da necessidade de extensão da solidariedade para com a sociedade receptora, e uma predisposição à mudança. Como a maioria dos japoneses viam a imigração de modo temporário, a predisposição à mudança diminuía, eles só pensavam em se adaptarem por um período no Brasil.

Vieira (1973, p. 168) desta que "Durante anos, vemos persistir difusamente a 'rivalidade entre os dois grupos', até que uma crise interna, resultante da derrota do Japão na Segunda Guerra Mundial, colocara a necessidade de uma reorientação de todo o grupo japonês". Com isso, as duas associações marilienses tentaram se unir, visando ampliar a solidariedade entre eles. Como resultado dessa união, foi conseguido um acordo: em 1932 se 
unificaram as associações na Marília Nihon-jin-Kai, que passou a ser orientada por membros de uma e de outra tendência.

Em 1935, essa mesma associação passa a ser chamada de Associação Japonesa de Instrução de Marília, e tem o principal objetivo de beneficiar a instrução primária e desenvolver o espírito de solidariedade entre brasileiros e japoneses.

Com o rompimento das relações diplomáticas entre Brasil e os países do Eixo, constituído pelo Japão, Alemanha e Itália que se uniram contra forças aliadas na Segunda Guerra Mundial, em 1942, os imigrantes japoneses que residiam em Marília também ficaram prejudicados, sendo eles alvo de várias represálias e impedidos de se reunirem em grupo.

Como explica Vieira (1973, p. 235),

\begin{abstract}
Os japoneses das zonas pioneiras foram duramente atingidos por essas medidas, tanto mais quanto estavam economicamente e culturalmente orientados para o Japão. Viram seus depósitos bancários congelados, proibida a alienação ou oneração de seus bens imóveis, privados do apoio das casas bancárias japonesas, suas cooperativas agrícolas sob regime de interventoria e todas as empresas de capital japonês compelidas à liquidação forçada ou colocadas sob a administração do Governo Federal. Foram também fechadas as escolas japonesas e as associações nipônicas.
\end{abstract}

Os efeitos da guerra se faziam sentir fortemente entre os japoneses habitantes do Brasil. Nessa mesma época, em Marília, foi realizada uma reunião na Associação Comercial com todos os agricultores e comerciantes que faziam parte de algum dos países envolvidos na guerra para esclarecer que estavam proibidas todas as transações que viessem efetuar pagamentos em dinheiro. Todos os pagamentos feitos a eles deveriam ser em cheques nominais e os japoneses obrigados a depositar a quantia no banco e só poderiam sacar o necessário para fazer pagamentos e com a apresentação do comprovante. Não podiam também falar a própria língua, reunirem-se em grupos de mais de três pessoas e, para se locomoverem precisavam do salvo conduto. Além disso, não podiam ouvir o programa japonês de rádio. Em muitas casas onde havia rádio e foi descoberto, a polícia confiscou.

Em 1951, após a Segunda Guerra Mundial, a Associação foi reaberta e a escola voltou a funcionar. Em 1952, foi feita uma nova eleição para a diretoria que permaneceu até 1960. Porém, nesse período, houve mudanças no nome dessa associação e em seu estatuto, mas sempre com a preocupação na instrução primária dos filhos de seus associados e com a manutenção da cultura e identidade japonesa. Em 1954, novamente, há uma mudança no nome da associação, que passa a se chamar Associação Nipo-Brasileira de Marília. Em 1959, com outra mudança, a entidade passa a nominar-se Associação Japonesa do Brasil de Marília. 
Em quase quarenta anos de existência, a Associação passou por muitas crises, várias eleições de diretorias e mudanças de nome. Entretanto, apesar de algumas alterações em seu estatuto, sempre resguardavam a preservação dos valores japoneses e a educação dos filhos.

Apesar de a Nipo ser a principal associação japonesa em Marília e representativa entre os imigrantes japoneses, havia poucos associados de Okinawa. Somente em 1962, um okinawano tem o cargo de diretoria. Os okinawanos, porém, possuem sua própria associação desde 1930, a Okinawa Kyokai de Marília, filial da Okinawa Kyokai do Brasil com sede em São Paulo.

A Okinawa Kyokai de Marília foi fundada nos primeiros anos da cidade, por volta de 1930, na mesma época em que Marília Nihon-jin-Kai surgiu, e com a finalidade de reunir as famílias okinawanas do município, então em número de 20 a 23. A associação só foi registrada depois da guerra, a 5/4/1952 (VIEIRA, 1973, p. 181).

Apesar de existir na cidade desde 1930, durante a guerra, a associação Okinawa Kyokai de Marília teve seus documentos queimados e toda a informação sobre o seu período inicial foi perdida. Fato lamentável como esse acontece comumente com acervos documentais e muito da história e da memória é perdida, dificultando a transmissão do conhecimento às gerações futuras e deixando lacunas irreparáveis à pesquisa científica e à escrita da história.

Segundo Vieira (1973, p. 165),

Tais associações "servem, não apenas como focos de tradição, mas são também canais de comunicação com a sociedade receptora". Essas associações têm o papel importante para que a identificação do povo japonês não se perca, mas também foram extremamente necessárias na transição dos imigrantes que chegavam ao Brasil sem conhecimentos do país para onde imigraram.

Quando essas associações foram criadas, tinham sua filiação limitada somente aos japoneses, pois visavam contribuir para a identidade e cultura dos japoneses, considerada por eles completamente diferente da identificação brasileira.

Mas, como bem aponta Vieira (1973, p. 165), "em algumas associações, os antigos padrões expressivos, tornaram-se mais limitados no seu alcance, não sendo um símbolo de identificação étnica em oposição à sociedade brasileira". Entende-se por padrões expressivos, normas, valores, comportamentos e um sistema de status específico que contribui para a identidade particular que se opõe à identificação comum com o sistema social inclusivo.

Com o passar do tempo, após maior adaptação dos imigrantes no Brasil, os japoneses começaram a participar das instituições brasileiras e, os brasileiros, por sua vez, também passam a integrar as associações japonesas. 
As associações também foram utilizadas pelos imigrantes como canais de comunicação com os brasileiros, auxiliando na transformação e representação do grupo que ela congregava, facilitando a solidariedade entre japoneses e brasileiros, podendo, com o passar do tempo, se tornar uma importante extensão da participação dos japoneses nas esferas institucionais da sociedade brasileira.

\title{
5 Informação, Memória e Documento: o acervo das associações japonesas de Marília
}

Sabemos que, historicamente, a produção e reprodução da cultura se dão pelo modo informacional, ou seja, os costumes e crenças são passados de um indivíduo para o outro por meio das histórias contadas por seus ancestrais e dos registros produzidos a partir dessas memórias. Nessas sociedades, a prática social usada para a disseminação da cultura pode ser considerada uma prática informacional, pois em toda interação humana há a necessidade de geração, organização, transferência e mediação de informação para que as histórias sejam disseminadas.

De acordo com Araújo (2001, p. 31),

\begin{abstract}
As práticas informacionais caracterizam-se através das seguintes ações: recepção (como ação de seleção), geração (como atividade de reapropriação, no sentido de agregar valor à informação) e transferência de informação (como ação de socialização da informação). Destaca que a informação deve ser gerada, transferida e recebida através de um processo educacional coparticipativo, possibilitando com isso a formação de um sujeito social com capacidade de desenvolver consciência de si e do mundo e, a partir daí, seja capaz de implementar ações políticas em diferentes níveis, desenvolvendo assim, uma cidadania ativa, ou seja, lutando pela possibilidade de criação, transformação e controle sobre o poder.
\end{abstract}

Desse modo, entendemos que quando um sujeito acessa uma informação, ele seleciona o que irá ou não utilizar de cada conteúdo. Com essa seleção, o indivíduo pode gerar uma nova informação e transferi-la a outros, agregando conhecimento, numa reapropriação do que foi acessado, ou seja, dando outro sentido e gerando uma nova informação e, consequentemente, um novo conhecimento.

Para que a cultura de um grupo não desapareça e sua identidade se transforme a tal ponto que deixe de ser sua representação, é natural que os indivíduos que fazem parte desse grupo guardem alguns materiais relativos à memória, como documentos de variados tipos: cartas, fotos, atas, objetos etc., que são importantes fontes históricas e de informação. Documentar, pois, é uma forma de materializar a memória mediante objetos físicos, gerando suportes materiais de informação. 
A construção e escrita de muitas histórias são baseadas em documentos físicos, guardados ao longo do tempo. O documento é, portanto, uma espécie de prova, testemunho que a memória coletiva utiliza para construir uma história. Podemos afirmar que o registro físico de um fato ou acontecimento é, dessa forma, de fundamental importância para a história.

Segundo Le Goff (1992, p. 535), “a memória coletiva e a sua forma científica, a história, aplicam-se a dois tipos de materiais: os documentos e os monumentos".

O termo latino documentum, derivado de docere 'ensinar', evoluiu para o significado de 'prova' e é amplamente usado no vocabulário legislativo. É no século XVII que se difunde, na linguagem jurídica francesa, a expressão titres et documents e o sentido moderno de testemunho histórico data apenas do início do século XIX. O significado de "papel justificativo", especialmente no domínio policial, na língua italiana, por exemplo, demonstra a origem e a evolução do termo. $O$ documento que, para a escola histórica positivista do fim do século XIX e do início do século XX, será o fundamento do fato histórico, ainda que resulte da escolha, de uma decisão do historiador, parece apresentar-se por si mesmo como prova histórica. A sua objetividade parece opor-se à intencionalidade do monumento. Além do mais, afirma-se essencialmente como um testemunho escrito (LE GOFF, 1992, p. 536).

Para Bellotto (2004, p. 35),

Segundo a conceituação clássica e genérica, documento é qualquer elemento gráfico, iconográfico, plástico, ou fônico pelo qual o homem se expressa. É o livro, o artigo de revista ou jornal, o relatório, o processo, o dossiê, a carta, a legislação, a estampa, a tela, a escultura, a fotografia, o filme, o disco, a fita magnética, o objeto utilitário etc., enfim, tudo o que seja produzido, por motivos funcionais, jurídicos, científicos, técnicos, culturais ou artísticos, pela atividade humana.

Podemos perceber, assim, que o documento pode estar em diversos formatos e, independentemente de sua materialidade, foi criado para fornecer dados e informações existentes. A especificidade para a qual o documento foi criado é que vai determinar seu uso, seu destino e se será ou não armazenado para que sejam preservados o processo social, cultural e administrativo de uma sociedade de modo que estes possam provar, testemunhar fatos vividos na história dos indivíduos.

De acordo com Le Goff (1992, p. 535),

A palavra latina monumentum remete para a raiz indo-européia men, que exprime uma das funções essenciais do espírito (mens), a memória (memini). O verbo monere significa 'fazer recordar', de onde 'avisar', 'iluminar', 'instruir'. O monumentum é um sinal do passado.

Um monumento é tudo aquilo que pode nos remeter ao passado, fazer viva nossas recordações de fatos vividos, tornar conhecido e valorizado um tempo em nossas memórias. 
Os monumentos estão relacionados especialmente a lugares, acontecimentos e a outros símbolos do passado que nos auxiliam a lembrar e a não esquecer.

O historiador Le Goff (1992, p. 546), esclarece que,

A história, na sua forma tradicional, dedicava-se a 'memorizar' os monumentos do passado, a transformá-los em documentos e em fazer falar os traços que, por si próprios, muitas vezes não são absolutamente verbais, ou dizem em silêncio outra coisa diferente do que dizem; nos nossos dias, a história é o que transforma os documentos em monumentos e o que, onde dantes se decifravam traços deixados pelos homens, onde dantes se tentava reconhecer em negativo o que eles tinham sido, apresenta agora uma massa de elementos que é preciso depois isolar, reagrupar, tornar pertinentes, colocar em relação, constituir em conjunto.

Documentar as ações humanas por meio de registros em suportes físicos resulta na materialização da informação, que a torna manipulável, classificável e codificável para que seja acessível, independentemente do tempo e do espaço. Nesse sentido, a invenção da imprensa no século XV muito contribuiu com as dimensões técnicas de criação, organização e preservação de documentos, acervos e arquivos para a história.

O documento não é inócuo. É antes de mais nada o resultado de uma montagem, consciente ou inconsciente, da história, da época, da sociedade que o produziram, mas também das épocas sucessivas durante as quais continuou a viver, talvez esquecido, durante as quais continuou a ser manipulado, ainda que pelo silêncio. $O$ documento é uma coisa que fica, que dura, e o testemunho, o ensinamento (para evocar a etimologia) que ele traz devem ser em primeiro lugar analisados desmistificando-lhe o seu significado aparente. $\mathrm{O}$ documento é monumento. Resulta do esforço das sociedades históricas para impor ao futuro - voluntária ou involuntariamente - determinada imagem de si próprias (LE GOFF, 1992, p. 548).

Inferimos que um acervo documental representativo de uma memória social, pode estar em vários locais e em diversos suportes, e eles podem dizer muito sobre a cultura e a história das pessoas e dos lugares nos quais estão inseridas.

Em pesquisa realizada na Associação Nikkei Clube de Marília, percebemos que, apesar dessa Associação promover vários eventos anualmente, não há grande preocupação em documentar e constituir acervos. Somente são confeccionados folders de divulgação do Japan Fest. Há também um Caderno do XXXI Campeonato Brasileiro Inter Clubes Infantil de basebol realizado nos dias 28, 29 e 30 de novembro de 2014 e o 65 Campeonato Brasileiro Intercolonial de Tênis de Mesa, que foi realizado entre os dias 23 a 25 de janeiro de 2015. Além disso, no acervo estão as atas datadas de 1991 a 2016.

Em ata de 01/12/1991 os membros do Conselho Deliberativo e os associados em geral da "Associação Cultural Nipo-Brasileira de Marília" deliberaram: 
01- Mudança de denominação da Entidade para "Associação Cultural e Esportiva Nikkey de Marília" ou Nikkey Clube de Marília.

02- Incorporação para efeito de unificação das Entidades "Esporte Clube Mariliense" e "Sociedade Esportiva e Cultural de Marília".

Alteração dos estatutos Sociais. Foi explanado os itens acima, bem como da necessidade de unificar as entidades existentes em Marília, ou seja, a própria "Associação Cultural Nipo-Brasileira de Marília" com o "Esporte Clube Mariliense" e com a "Sociedade Esportiva e Cultural de Marília, a fim de formar uma associação forte coesa e acima de tudo a unidade entre os associados, deixando assim uma base patrimonial-financeira sólida para os nossos descendentes, tendo em vista que os dirigentes e os associados das três entidade se confundem, todos pertencendo e trabalhando em prol das entidades supra mencionadas, cujo objetivos são idênticos e afins, após discussão e debates, colocou em votação onde obteve 71 votos á favor da unificação e um voto de abstenção, ficando assim aprovado a mudança de denominação social para "Associação Cultural e Esportiva Nikkey de Marília" ou simplesmente Nikkey Clube de Marília.

Da denominação, fundação, sede fins e duração.

Tem por fim:

I - Promover as atividades educacionais e culturais, mantendo sempre o intercâmbio e atividades entre a cultura nacional e a japonesa, sempre com o espírito fraterno, primando pelo bem-estar dos associados e da comunidade.

II - Promover o desenvolvimento das atividades sociais, amparo social e atividades recreativas.

III - Difundir e promover a prática de todos os esportes amadores, olímpicos ou não, competitivos e recreativos, bem como os exercícios físicos e atléticos.

$\S$ único- Fica terminantemente proibida a prática de jogos de azar e atividades ilícitas no recinto do "N.C.M." (Nikkey Clube de Marília).

3ㅇ o "N.C.M.", terá sua duração por tempo indeterminado e somente poderá ser dissolvido por decisão de $2 / 3$ dos sócios em pleno gozo de seus direitos, reunidos em Assembléia Geral Extraordinária, convocada para essa finalidade.

$\S$ único- Em caso de dissolução do "N.C.M.", todo seu patrimônio líquido será dividido entre as instituições de beneficiência, legalmente constituídas e existentes de fato, em funcionamento na cidade de Marília, cuja a distribuição far-se-á obedecendo o critério que a Assembléia estabelecer.

4ㅇ O "N.C.M.", adota nos seus uniformes, pavilhão e flâmulas, as cores branca, vermelha e azul.

Consideramos que as atas das reuniões do Conselho Deliberativo representam os registros documentais de maior expressividade temporal do que ocorre na Associação, especialmente em relação às eleições da diretoria, como veremos a seguir no quadro 1. 
Quadro 1 - Resumo dos conteúdos das Atas

\begin{tabular}{|c|c|}
\hline Data da Ata & Deliberação \\
\hline 01/04/1996 & $\begin{array}{l}\text { Nomeado o Conselho Deliberativo e a Chapa Integração foi eleita para o } \\
\text { período de } 1996 \text { a } 1998\end{array}$ \\
\hline 03/04/1998 & $\begin{array}{l}\text { Nomeado novo Conselho Deliberativo e a Chapa Integração foi reeleita } \\
\text { para o período de } 1998 \text { a } 2000\end{array}$ \\
\hline $31 / 03 / 2000$ & $\begin{array}{l}\text { Nomeado um novo Conselho Deliberativo e foi eleita a Chapa União } 2000 \\
\text { para o período de } 2000 \text { a } 2002\end{array}$ \\
\hline $22 / 03 / 2002$ & $\begin{array}{l}\text { Nomeado Conselho Deliberativo e a Chapa União } 2000 \text { foi reeleita para o } \\
\text { período de } 2002 \text { a } 2004\end{array}$ \\
\hline $20 / 12 / 2003$ & Reforma do Estatuto Social \\
\hline $30 / 03 / 2004$ & $\begin{array}{l}\text { Nova eleição do Conselho Deliberativo e Fiscal a Chapa Renovação } 2004 \text { foi } \\
\text { eleita para o período de } 2004 \text { a } 2006 .\end{array}$ \\
\hline $30 / 03 / 2006$ & $\begin{array}{l}\text { Nova eleição do Conselho Deliberativo e Fiscal, eleita a Chapa Integração } \\
2006 \text { para o período } 2006 \text { a } 2008 \text {. }\end{array}$ \\
\hline $31 / 01 / 2008$ & $\begin{array}{l}\text { Eleição do Conselho Deliberativo e Fiscal. Novamente eleita a Chapa } \\
\text { Integração para o período de } 2008 \text { a } 2010 \text {. }\end{array}$ \\
\hline $28 / 01 / 2010$ & $\begin{array}{l}\text { Eleição do Conselho Deliberativo e Fiscal. Eleita a Chapa União para o } \\
\text { período de } 2010 \text { a } 2012 \text {. }\end{array}$ \\
\hline \multirow[t]{2}{*}{$17 / 12 / 2013$} & $\begin{array}{l}\text { Eleição do Conselho Deliberativo e Fiscal. Eleita a Chapa União para o } \\
\text { período de } 2013 \text { a } 2015 \text {. }\end{array}$ \\
\hline & $\begin{array}{l}\text { Nova eleição do Conselho Deliberativo e a Chapa União foi reeleita para o } \\
\text { período de } 2016 \text { a } 2017 \text {. }\end{array}$ \\
\hline $15 / 12 / 2011$ & $\begin{array}{l}\text { Houve uma reforma parcial do Estatuto Social, renovando } 1 / 3 \text { dos } \\
\text { membros do Conselho Deliberativo e a Assembleia Geral passa a se reunir } \\
\text { de dois em dois anos na primeira quinzena de dezembro para eleição. }\end{array}$ \\
\hline
\end{tabular}

Fonte: elaborado pela autora.

O Estatuto Social foi reformado em 20 de dezembro de 2003. Destacado, conforme a ata:

A "Associação Cultural e Esportiva Nikkey Clube de Marília" fundada pela coletividade Nipo-Brasileira de Marília, com registro em 01/04/1935, com denominação de "Associação Japonesa de Instrução de Marília, em 20/11/1959 passou a denominar-se "Associação Japonesa do Brasil em Marília" em 14/05/1963 passou a denominar-se "Associação Nipo-Brasileira 
de Marília" e, em 07/02/1992 foi registrado com denominação "Associação Cultural e Esportiva Nikkey de Marília".

Em seu estatuto foi acrescentado que em caso de dissolução do "N.C.M.", o acervo que constitui o "Memorial do Imigrante Japonês em Marília", será doado a prefeitura de Marília para os Registros Históricos de Marília, a fim de perpetuar esta memória.

As atas anteriores a 1991, lamentavelmente, não estão no acervo da Associação e não foram localizadas. As informações constantes nas atas pesquisadas, nos levam a constatar que são bem pontuais, se referindo principalmente a eleições dos conselhos consultivo e fiscal.

A Associação só tem registros após a incorporação das entidades. Estas estão guardadas e organizadas no acervo da própria Associação, juntamente com as fotos e folders de divulgação. Para ter acesso a esses documentos, é necessário formalizar pedido junto a diretoria do Clube e o mesmo será discutido em Assembleia que, juntamente com os membros, tomará a decisão de liberar o acesso ou não.

Mesmo considerando o desaparecimento de muitos documentos administrativos, como as atas, infere-se que a preservação do acervo da Associação Cultural e Esportiva Nikkey Clube de Marília é de grande importância para a cidade, bem como para a preservação da memória e cultura japonesas na região, como um dos meios com que a identidade dos seus antepassados será repassada aos mais jovens, podendo contribuir com a perpetuação da cultura e das tradições do grupo, conforme era a vontade dos antepassados.

A Associação Esportiva e Cultural Okinawa de Marília (AECOM) não utiliza nem um tipo de classificação/catalogação na organização e gestão dos seus documentos. Algumas fotos, vídeos e atas estão guardados com os associados e antigos presidentes em suas residências. Tivemos acesso a algumas dessas fotos e imagens durante a pesquisa ao contatar com os seus guardiões. Não tivemos contato com as atas da Associação, com a justificativa de que as mesmas contêm informações sigilosas referentes a entidade e a seus sócios.

Além dessas dificuldades relatadas em acessar os documentos, esse fato se torna ainda mais restritivo à pesquisa porque, durante um incêndio, muitos documentos foram perdidos e só tivemos acesso a informações sobre esse período através das entrevistas que foram realizadas, a serem apresentadas em outro momento no desdobramento deste estudo.

\section{Considerações Finais}

Diante do foi discutido, podemos afirmar que a memória realmente se situa entre o passado e o presente, e se constitui em um processo de reconstrução e transformação de experiências vividas e continuamente relembradas. 
A memória, portanto, é essencial para a construção da identidade individual ou coletiva. Dessa forma, para que a história reflita como o passado influencia a vida no presente e suas memórias se tornem conhecidas e a identidade preservada, os indivíduos repassam, uns para os outros, suas vivências, enfatizando a história de seus ancestrais e evidenciando sua identidade, utilizando-se, para isso, dos documentos produzidos no decorrer de suas atividades. Porém, especialmente no caso das associações estudadas, mesmo com a modernidade evidente dos tempos atuais, ainda hoje a oralidade e a narrativa são um importante meio para se passar as experiências, pois ainda não há uma preocupação evidente em se constituir acervos documentais.

A memória de um grupo é sempre algo em construção, pois continuamente novos elementos são agregados, surgem questionamentos, indícios e lembranças a serem investigados e acrescentados. Outras percepções e olhares também se somam aos sucessivos estágios da memória. Portanto, podemos concluir que o ato de relembrar é dinâmico e as histórias se cruzam continuamente.

Nesse sentido, a própria existência das associações e sua manutenção ao longo dos anos pode ser considerado como um mecanismo relativo ao que Pierre Nora (1993) definiu como lugares de memória. A associação funcionaria como um lugar de memória não apenas pela preservação da memória documental que, neste caso, demonstrou-se insuficiente, mas principalmente pela possibilidade de estabelecimento de um espaço de rememoração do vivido e de construção e reconstrução de conhecimento.

Podemos concluir, então, que nos casos onde a documentação preservada não é suficiente para traçar um panorama consistente da trajetória de um grupo, é na memória individual que serão encontrados elementos informacionais que permitam ampliar a interpretação sobre os fatos ocorridos.

É importante ampliar, portanto, o escopo de pesquisa e, na medida do possível, aplicar metodologias de coleta de entrevistas pessoais para complementar a informação obtida nos documentos.

Sem dúvida alguma, tanto os documentos históricos produzidos e guardados pelas associações japonesas de Marília, quanto as narrativas dos imigrantes e seus descendentes constituem-se como importantes fontes de pesquisa para a compreensão dos processos migratórios e da cultura desses povos, além de permitirem a organização de acervos e da memória documental, essenciais para pesquisas históricas e sobre memória no âmbito das Ciências Sociais e Humanas. 


\section{Referências}

ARAÚJO, A. E. Informação, sociedade e cidadania: práticas informacionais de organizações não governamentais - ONGS brasileiras. Informação \& Informação, Londrina, v. 6, n. 1, p.31-54, jan. /jun. 2001.

BELLOTTO, L. H. Arquivos permanentes: tratamento documental. 2. ed. Rio de Janeiro: Editora FGV, 2004. 320 p.

CASTELLS, M. O poder da identidade. São Paulo: Paz e Terra, 1999. 530 p.

HALBWACHS, M. A Memória Coletiva. São Paulo: Vértice, 1990. 189 p.

HANDA, T. O imigrante japonês: história de sua vida no Brasil. São Paulo: T. A. Queiroz; Centro de Estudos Nipo-Brasileiro, 1987.

LE GOFF, J. História e memória. 2. ed. Campinas: Editora UNICAMP, 1992.

NAKAMURA, T. N. Memória e identidades nipo-brasileiras: cultura pop, tecnologias e mediações. São Paulo: M. T. Nakamura, 2013. 98 p.

NORA, P. Entre memória e história: a problemática dos lugares. Projeto História: Revista do Programa de Estudos Pós-Graduados em História e do Departamento de História da PUC-SP, São Paulo, n. 10, p. 7-28, dez. 1993.

POLLAK, M. Memória e identidade social. Estudos históricos, Rio de Janeiro, v. 5, n. 10, p. 2002012, 1992.

SAKURAI, C. Imigração tutelada: os japoneses no Brasil. Campinas: [s.n.], 2000.

SAKUARI, C.; COELHO, M. P. (Org.). Resistência \& integração: 100 anos de imigração japonesa no Brasil. Rio de Janeiro: IBGE, 2008.

SILVA, V. H. M. K. Um Jornal entre Brasil e Japão: a construção de uma identidade para japoneses no Brasil e brasileiros no Japão. São Paulo: UFSCar, 2008, $171 \mathrm{f}$.

VIEIRA, F. I. S. O japonês na frente de expansão paulista: o processo de absorção do japonês em Marília. São Paulo, Pioneira, Ed. da Universidade de São Paulo, 1973. 272p.

Recebido/Recibido/Received: 2016-04-29

Aceitado/Aceptado/Accepted: 2016-06-30 